\title{
INHERENT WISDOMS AND THE ROLES OF SACRED SPACES IN SPATIAL ORGANIZATION OF VERNACULAR HOUSES
}

\author{
C. Chiranthanut $1, *$ \\ ${ }^{1}$ Faculty of Architecture, Khon Kaen University, Thailand - wchant@kku.ac.th
}

Commission II - WG II/8

KEY WORDS: Sacred Space, Spatial Hierarchy, Local Wisdom, Belief, Spatial Organization, Tai-speaking

\begin{abstract}
:
After nearly twenty years of studying vernacular houses in the field, the rapid loss of beliefs in sacred household spaces that used to influence people's roles in spatial organization has been found. This article thus presents the various roles of inherent wisdoms in the house by revealing the ancestors' living wisdoms transferred through the use of sacred space as the tool for the control over the order of household members. The research was performed by means of the qualitative method and comparison of information collected from the field surveys of the vernacular household patterns of the Tai-speaking ethnic groups living in Southeast Asia from 2000 until the present. The results reveal the relationships between the sacred space and spatial organization in the house. The household area in the front has a higher intersectional sacred power than the back part. The former is associated with the family head and males, while the latter is associated with socially inferior members such as daughters, sons-in-law, daughters-in-law. In addition, it can be said that the sacred places are used as a stratagem for transferring lifestyle wisdoms and household patterns until a group's identities are formed. This study indicates the importance and urgency to conserve intangible cultural heritages that are fading with urbanization. Otherwise, a risky situation towards incapacities to retrieve valuable roots of thoughts could happen in the near future if there is no tool to conserve the intangible cultural wisdom heritages such as the household sacred spaces.
\end{abstract}

\section{RATIONALE}

Tai-speaking people dispersedly living in different watershed areas in Southeast Asia including Yunnan in China, Vietnam, Thailand, Myanmar, and Laos. They are found to have common cultures but are differently called such as: Tai Dam, Tai Puan, Tai Yuan, Phu Tai, Tai Lao, Tai Nua, Tai Lue, Tai Yai (Figure 1). These ethnic minorities have similar lifestyles, i.e., growing rice, eating rice, living in a wooden house with a high open basement (Figure 2), believing in the supra-naturals, mysteries, ghosts, and ancestors. Presently, most of them are found being Buddhists and hence performing both Brahmin and Buddhism rituals. Their gender-related culture is found to be maleoriented, that is, males are superior than women. Traditionally, the in-laws live under the same roof after marriage or until they are ready to move away to build their own family in a new house. This article presents the phenomena related to social practices, rituals and festive events through the study of vernacular houses of the eastern cultures that risk being declined from the rapid globalization and urbanization impact. The field survey information points out that the sacred spaces in the vernacular houses of Tai-speaking people are intangible cultural wisdom heritages the sacred spaces in the vernacular houses of Tai-speaking people are part of the intangible cultural wisdom heritage that have significant roles in the architectural formation of vernacular houses. They are the tool for controlling people's behaviors and ways of living with direct relation between the status of family members and the household zones. The belief of sacred space has been inherited by means of the thinking and reproduction systems, transferred from generation to generation and clearly reflected in the household spatial organization. As a consequence, the identity of each ethnic group's house plan has been formed. The sacred space in vernacular architecture is thus valuable and worth the awareness as an important tool for the study, understanding, retrieval, and distinguishing of the ethnic specificities and house plans resulting from the beliefs that are related to the sacred places intersectionally formed with identities.

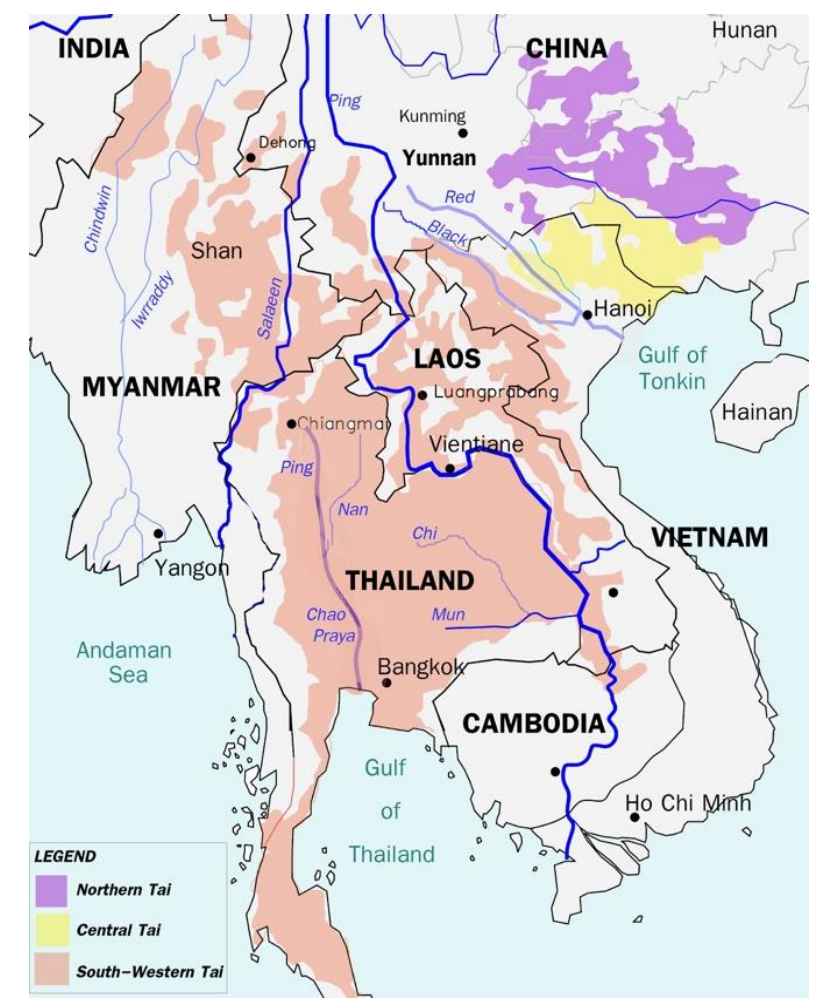

Figure 1. A map of the Tai-speaking areas in Southeast Asia.

\footnotetext{
* Corresponding author
} 


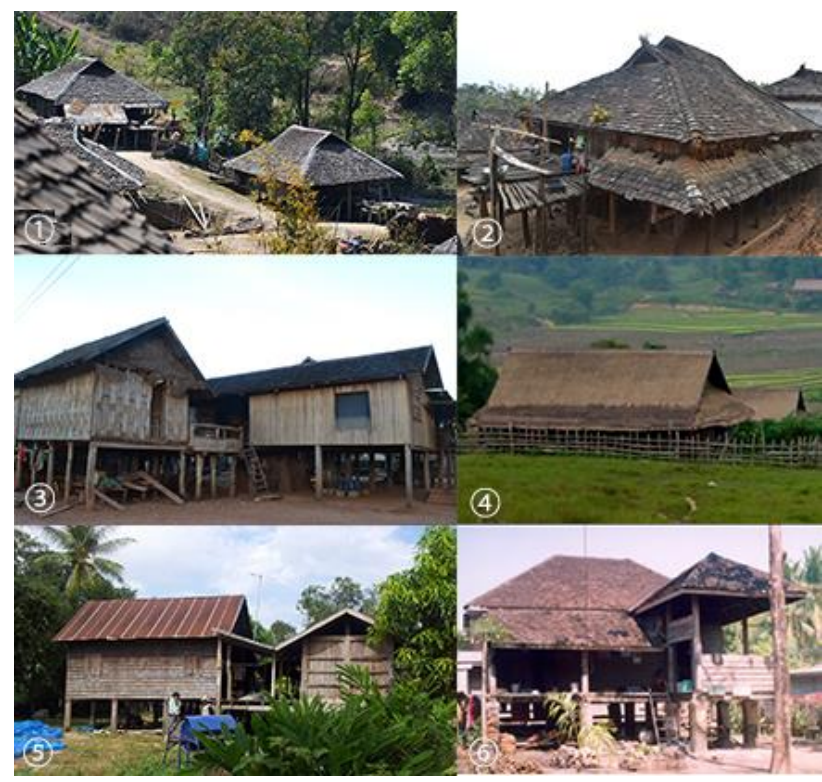

Figure 2. Image of the Tai-speaking vernacular houses (1)(2) House in Yunnan, (3)(4)House in Laos, (5)(6)House in Thailand.

The researcher's nearly twenty-year field survey of the vernacular houses reveals that the belief of sacred spaces in the house that used to play a role in house management is declining rapidly. Presently, there is a lack of ritual succession, and the definition of phenomena and the roles of the sacred places differ from the past. For instance, the sacred space has become part of the house decoration, or the house plans have changed from the traditional one. In many cases, it is impossible to retrieve the former conceptual framework that used to control management of usage zone in the house. The decline of sacred spaces and rituals, the total loss of traditional concept, the incapacity of household members to explain the function of each place that still exists are due to the lack of ritual succession, especially at the sacred places. Household area usage has been permanently adjusted, and these phenomena are occurring rapidly. This is considered a risk in the academic circle and the future study of the conservation and succession of vernacular houses. This article therefore presents the inherent wisdoms in the house by indicating the ancestors' attempts to transfer the ways of living through the use of sacred space as the stratagem to control and manage the order of the members. The study raises awareness of the importance of vernacular architecture in the sense that besides the attempts to conserve physical architecture, which is the tangible cultural heritage, the world academicians should expedite their studies on intangible cultural heritages such as the household sacred spaces that are declining with time. The tool for the study and conservation of intangible cultural heritages should be developed in time for the rapid cultural changes that are occurring at present.

\section{LITERATURE REVIEW}

Cultural heritage can be both tangible and intangible. Since the 1970s, awareness of intangible heritages has become more of an issue. UNESCO defines intangible heritage as the practices, representations, expressions, as well as the knowledge and skills that communities, groups, and in some cases, individuals recognize as part of their cultural heritage. Intangible heritage is well known as "living cultural heritage" where it represents the living characteristics of cultural heritage (World Heritage Definitions, 1972; UNESCO, 2003).
Intangible cultural heritages are classified into 5 different types, namely, 1) Oral Traditions and Expressions, 2) Performing Arts, 3) Social Practices, Rituals and Festive Events, 4) Knowledge and Practices Concerning Nature and the Universe, 5) Traditional Craftsmanship. Attempts have been made to promote the conservation of cultural wisdom heritages since the past, while people have tried to understand the values and the formation of clear identities. Cultures are dynamic, flexible and subject to changes with the arriving influences. There are, therefore, risks of changes of the former and traditional roles of cultural heritages and eventually risks of losses (Unesco, 2003; Wisudthiluck, 2017).

Johnson (1996) defined local wisdoms as a set of knowledge created and inherited from generation to generation. These bodies of knowledge have been developed and disseminated within one's group and become the fundamental practices and cultures which can be both tangible and intangible. It can be said that cultures are created and stipulated by man and can be an object, a method, a thinking system that sets behaviors and a social system that becomes the symbolic of that society, transferred to younger generation, reproduced, redone, as the belief to hold on to and practice. People learn the appropriateness of their actions. Intangible cultures include spoken language, a set of beliefs, world vision, tradition and customs. Vernacular architecture is considered tangible, but it contains a lot of intangible cultures, especially the beliefs that are associated with the sacred space and the spatial organization role. This is inherited from one generation to the next with rituals that reflect the belief towards each sacred space.

Tangible vernacular architecture results from man's self adjustment wisdom continually practiced over time. Amos Rapoport (1969) pointed out the importance of vernacular architecture as the tool for the study of socio-cultural force, which is the fundamental element or the independent variable of key architectural formation of religion and belief, interrelation among man, nature, and the environment, social structure with its complex relationship that influences selfadjustment, alteration, and formation of vernacular architecture rather than the elements behind topography, climate, location, man's basic needs, construction materials and technology, and economics. Vernacular architecture is the consequence of the desire. It is the creation of common identity and group rather than the forming of individual identity. Vernacular architecture in China, Japan and countries in the Oceania are some of the examples used by Rapoport to demonstrate this socio-cultural force. The beliefs and sacred space are the key parts in spatial organization. We are able to study the concept of beliefs via the prioritization of usage areas that correlate to the sun's orientation, social status of household members, movement or existence in order to protect or bring the good and the bad as manifested by the sacred things.

Anthony Lawlor (1994) stated that man believes in supranatural beings and frequently stipulates different characteristics of ritual places, which range from religious venues as a result of the beliefs of big groups of people, for example: temple, monastery, shrine. Meanwhile, man believes and acts at the place close to us. In a house, there is the concept of creating the sacred place which is called the temple in the house. Beliefs and sacred spaces can be found in many patterns, ranging from an altar, a corner of a room, the level of 
the place. It can be said that sacred space means the area designated to differ from other places, with rituals or practices that specify the place as a sacred space. Paul Oliver explained beliefs and religions in the Encyclopedia of Vernacular Architecture of the World (1997) as consent and acceptance without hesitation over the right or wrong, without any necessity to prove or any evidence. Religion is defined as a set of beliefs of the supranaturals that can bring the good and the bad to an individual or his group. There are different levels of beliefs such as gods, ghosts, ancestors. The location of the belief space can be found in a house, and this is the place for the ritual that shows respect towards what one believes, worships, and thinks of as a sacred space. The sacred space has a role in the setting of spatial use and organization and is associated with the social status of the members.

Since vernacular architecture is information as well as an important tool for the understanding of man's adjustment in the environment, it indicates that the culture traits and attributes are key elements influencing architectural identities. We are able to learn the local wisdoms assimilated through time with reproduction and development into different patterns that become the foundation for the study of man's thinking development through vernacular architecture of each period. There are multiple cultures and hence the understanding of the background of identities and social traits via architecture will be the major root for the existence of man in the future. These bodies of knowledge can be used for the development of sustainable future accommodation. The world academicians should expedite their studies on intangible cultural heritages such as the sacred space in the household that is becoming declined in order to catch up with the rapid cultural changes in the world today.

\section{RESEARCH METHODOLOGY AND FRAMWORK}

This study was based on the qualitative research method and comparison of information collected from the field surveys of vernacular houses of Tai-speaking people living in Southeast Asia, especially in Thailand, Lao, Myanmar, and China Yunnan from 2000 until the present.

The study framework was delineated to the sacred spaces of the household. Various locations, patterns or characteristics of the households were recorded together with unstructured interviews, participatory observation and non-participatory observation. The succession of beliefs and rituals related to the sacred spaces through household members and children and the roles of sacred places in spatial organization were also investigated.

Implementing a qualitative approach, the research methods of the study consist of descriptive and analytical methods. Firstly, the idea framework is generated through related documents and literature review. Secondary, houses measuring, the household sacred spaces mapping, locations and patterns or characteristics of the sacred places documenting, household organization observing, and face-to-face interviewing have been conducted within the field study.

Finally, the analysis conducted merely on the sacred spaces in relation to the conceptual framework. Findings show the relations between the sacred space and spatial organization in the house.

\section{RESULTS OF RESEARCH AND ANALYSIS ON THE ROLES OF SACRED SPACES OVER THE CONTROL OF HOUSEHOLD SPATIAL ORGANIZATION}

\subsection{Locations and the roles of sacred spaces on household} spatial organization

The recording of locations and characteristics of the household sacred spaces in the vernacular houses of Tai-speaking people including Tai Lue, Tai Dam, Phu Tai, Tai Puan, Lao, Tai Isan, Tai Yuan, Tai Nua, Tai Yai, Thai (Central Thai) and the studies of information related to the patterns and locations of the sacred spaces as shown in Table 1 shows that there are more than one sacred space in certain ethnic group's vernacular houses, such as the houses of Tai Puan and Tai Dam where both the ghost room and the major fire stove are found. The following sacred places have been recorded:

4.1.1 The major pillar: the first pillar or the pair of the first pillars erected in the house. When a house is built, a ritual of major pillar erection is always practiced. Auspicious items are tied to the major pillar, and these items may deteriorate with time. What remain are the beliefs and rituals represented by worshipping and praying on every Buddhist holy day. This pillar is considered the most important thing in the house. It is usually located as the second pillar from the front part, and is where the heads of beds are oriented toward, since it is considered the highest level. The area closest to this pillar in a bedroom is where the head of the family or the house owner sleeps. Further toward the back are the places where family members sleep, each of whose status is in hierarchical order, namely, father, mother, sons, daughters, sons-in-law and daughters-in-law.

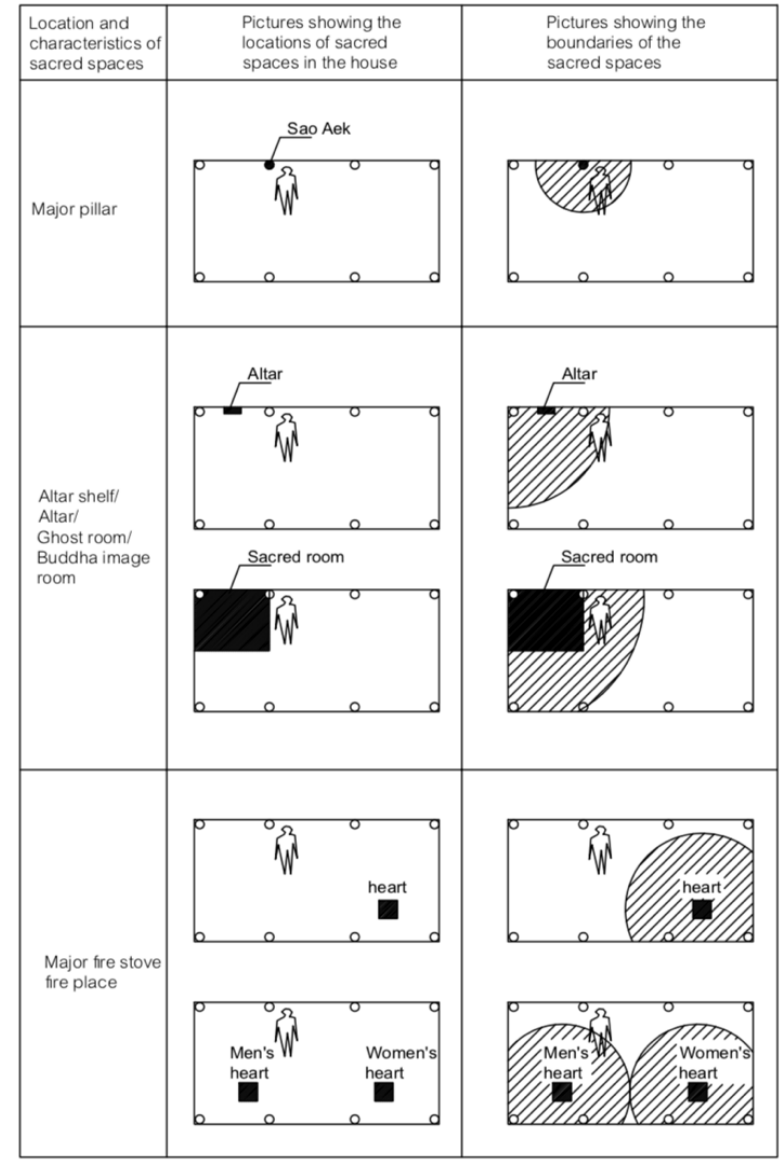

Table 1. Conclusion of locations and the roles of sacred spaces on household spatial organization 
4.1.2 The ghost room, the Buddha image room, altar shelf, altar: The ghost room and the Buddha image room are usually at the front of the house next to the wall where the head side of the bed is oriented toward, and frequently near the major pillar. The location of the ghost room of Tai Dam and Tai Puan are more special, i.e., the room is relatively dark with no opening. Inside the room stand items in remembrances of the ancestors and the worshipped ghosts, and ritual offerings. The tai-speaking ethnic groups who worship Buddhism have a Buddha image room or sometimes only an altar shelf or an altar. The shelf and the altar are small, fixed to the wall or placed on the floor adjacent to the wall at the head side of each bed. These are within the range of the first pillar. Near the location of these altars, the head side of each bed is oriented. Normally, worshipped items are placed on the altar shelf such as a Buddha image, items for ancestors' remembrance such as bone ash. If there are two shelves, the Buddha image is placed on the higher shelf. In the past, people keep ancestors' bone ashes, but today, these are kept at a temple fence.

In general, the sacred space here is considered a forbidden area, denoting the zones for outsiders and insiders, house owners, family leaders, house inheritors. Women, the in-laws, and outsiders are strictly not allowed to the place. A family's social status allows each member to know his or her roles and duties, obey their superiors, and learn how to build a prosperous family from the parents. When one becomes a house owner, the person is able to use these spaces, and the practice is repeated from generation to generation.

4.1.3 The fire stove or the household stove: The survey shows that in cold climate, people install a household fire stove in the house. In general, only one stove is found. The place associated with the stove and is used for cooking involves women. Tai-speaking people believe the stove is a sacred item and must be respected. A stove is female and resembles a mother. It is defined as the warmth and the source of life power in terms of household foods. For Tai Dan and Tai Puan, there are 2 fire stoves separated for men and women. The men's stove is placed in the front part of the house, while the women's stove is placed at the back. The men's stove of Tai Puan is very important and must be kept on fire until it is called "the breath of the house'. One reason is that Tai Puan lives in cold climate nearly all year round. The belief to keep the stove alight is to keep the house warm for the whole year.

The results of the study above reveal the information regarding the locations and common characteristics of major sacred spaces in vernacular houses. Most of the sacred spaces are the house's components in which wisdoms are inherent; they are the tools for and have their roles in managing and regulating the house's structural organization. This demonstrates the relationships among man, nature, the environment and the social structure, which are complicated and at the same time affect self-adjustment and formation of vernacular architecture.

It has been found that we are able to understand the patterns of vernacular architecture from sacred spaces, which, in details, differ from one ethnic group to another. The identity patterns thus far emerged, which however, gradually declined and thus could lead to losses of chances for cultural understanding in the coming future.

\subsection{Sacred Space as the tool for Household Spatial Organization and Inherent Wisdoms}

People generally are aware that vernacular houses are the results of man's adjustment towards the surrounding context through problem solution and repetitions from one generation to the next, until the pattern of a vernacular house was formed and inherited. If only regulations were used and forced to remember and practice, - as were the cases of house plan, duties and system for members to live together - they would not exist for a long time. Thus, a systematic recording system is required. Incorporating the belief of the sacred things with household management is the intelligence and wisdoms in various items that lead to effective and continual inheritance. The accompanying rituals also reiterate the recognition of surrounding items, both the environment believed to tie man and the nature and the ancestry that links one generation to the next, leading to unity and harmony. People therefore live together with respect towards one another and keep within one's decent boundary. The inferiors learn from the elders in family care. The older generation's traditions and customs have been absorbed by the younger generation that lives under the same roof. When the latter leave to build their own families, they would bring with them the living patterns and suitable house construction. Hence, sacred spaces control spatial organizations in the house. The comparative study of the horizontal house orientation shows 4 orientation that reflect spatial organization of Tai-speaking ethnic groups (Figure 3): the front, which is the head side of the bed and the back or the feet side. The concept of sacred space and the scope of sacred powers people must respect are associated with the members' social status and the inherent wisdoms of house management, which are as follows:

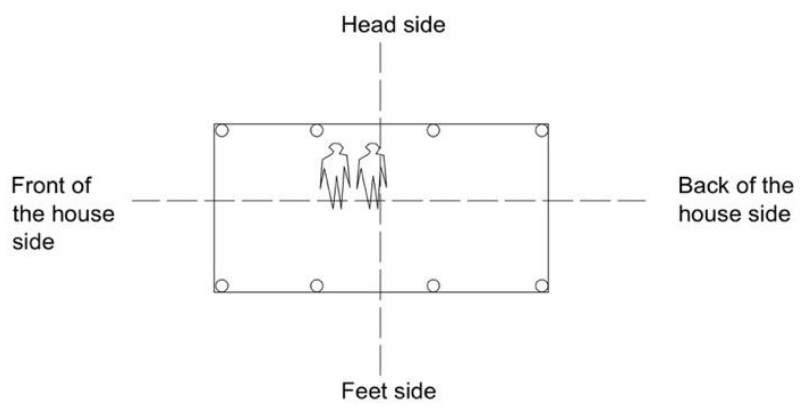

Figure 3. Household spatial organization

4.2.1 Household Members' Behavior Control: Two sorts of sacred spaces are situated at the front part of the house, namely, 1) the major pillar (sao aek) and 2) the ghost room or the altar shelf/altar. Thus, these spaces occupy the front part of the house and denote the living system of the family. The sacred spaces control the behaviors of the members. The house owner, men, monks, and shaman can use the area, whereas the inferior members including daughters and sons-in-law, and daughtersin-law use the areas at the back of the house. Nevertheless, as discussed earlier, the sacred spaces are considered forbidden areas that designate outsiders and insiders, house ownership, leadership, and inheritance of the house. The knowledge of household status enables each member to understand his or her duties and role, obey the superiors and learn to build one's own sustainable family after the father and mother. One will change the status after a family has been built, and that is when he can be the head of the family. This repeats itself in the next generation and is the house pattern, which is the stratagem used to retain intangible cultures through the house that is tangible. 
4.2.2 Health and hygiene: The separation of the house into the front - the direction of the head side of the bed - and the back or the feet side has its own clarified implication. The placing of the altar shelf and sacred items at the front part of the house means regular cleaning and ordering since it is otherwise considered disrespect towards sacred items, unseen divines and the ancestors who protect the household members. The area is used as the sleeping place and a ritual space. The ritual area can be used as the sleeping place of the house owner and the son. It has to be kept clean at all times. The house owner is respected as an important person, a laborer who teaches and cares other members. The front part also functions as the guest welcoming space, thus, if it is dirty the guests would regard the family with disdain. On the contrary, the back part of the house is designated as the washing and cooking area, and also for giving birth to a child. Thus, the place is filled with stains and deserves being at the back. Since the space is dirty, it may bring something devil. However, the fire is considered sacred as it provides light, cleanliness, warmth and food. The fire stove is a sacred item that guards the back of the house. Spatial organization designates daughters and the in-laws to principally use this area.

\subsubsection{Relationships in Social Systems, Ancestry, and} Love and Commitment: Houses of Tai-speaking ethnic groups allow connection of family members as well as their love towards the ancestors. Houses are thus a space for psychological repose that unites everyone, offering security and safety with the ancestors' protection. When the father and mother died, the children inherit the house. As being practiced, the younger child inherits the house as this person has taken care of the father and mother until they die. The respect is paid to the bone ashes, pictures, clothes and belongings; these articles are kept on a shelf at the head side of the bed at the front part of the house, denoting implications of protection and respect. The ties lead to house maintenance, and the children who have settled down away from home usually return to pay respect to the ancestors. Therefore, relationship still remains, and practices are similar to what the children learned from the former house with continuous rituals and house patterns from generation to generation.

\section{CONCLUSION}

The study above reveals the patterns of vernacular houses that have the order, system, and dimension of beliefs as the controlling tool over the spatial organization, which is performed through the sacred spaces and members' social status related to the use of the spaces (Figure 4).

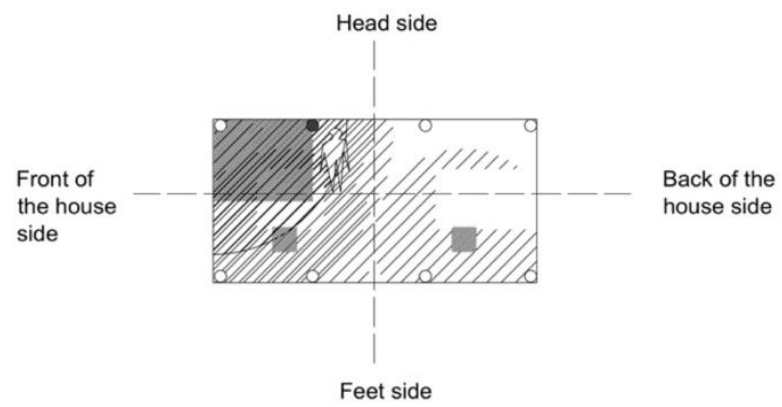

Figure 4. Relationships between Sacred Space and Household Space
The positioning of a ghost room in the front make outsiders feel obliged to pay respect to the place. The space of the ghost room is sacred and allows only the household head and males to use, whereas females, sons- and daughters-in-law would use the back part of the house. Spatial organization that is based on the sacred space creates clear circulation patterns of household members. It enables analysis of wisdoms in the use of beliefs as the mechanism to control various activities from the laying of family structure with different priorities and different duties. Sacred spaces are considered the most important among other zones and need to be regularly cleaned. As a result, there are clean zones in the house that demonstrate good hygienic management.

This study indicates the values and important roles of the sacred spaces in spatial organization. At present, there are changes of the space usage in the house resulting from the adjustment of people to the new arriving social context.

The roles and importance of physical elements that represent the sacredness of a place have continuously declined especially in urban communities. This article is aimed to stress that besides the attempts to conserve physical and vernacular architecture which are tangible, studies of intangible cultural heritages should be expedited before they fade away. Tools and approaches for the study and conservation of intangible cultural heritages should be developed in time for the present days' rapid cultural changes.

\section{REFERENCES}

Lawlor, A. 1994. The Temple in the House: Finding the Sacred in Everyday Architecture. New York: A. Jeremy P. Tarcher.

Oliver, P., 1997. Encyclopedia of Vernacular Architecture of the World. UK.: Cambridge University Press.

Rapoport, A., 1969. House Form and Culture. Englewood Clifts, N.J.: Prentice-hall.

UNESCO. Article 2 of the Convention for the Safeguarding of the Intangible Cultural Heritage. 2003.

Wisudthiluck, S., 2007. Heritage of the Nations: Lessons Learned from the Neighboring Countries. Bangkok: Princess Maha Chakri Sirindhorn Anthropology Centre (Public Organisation).

World Heritage Definitions. 1972. United Nations Convention Concerning the Protection of the World Cultural and Natural Heritage, General Conference and Its 17th Session, Paris, 16 November 1972. 